\title{
Validation of the Brazilian version of the Attentional Function Index
}

\author{
Carla Klava dos Reis Dutra ${ }^{1}$
}

Edinêis de Brito Guirardello²

\begin{abstract}
Objectives: To assess the reliability and validity of the Brazilian version of the Attentional Function Index. Method: Methodological study. The sample was made up of 138 students from an undergraduate nursing course. The psychometric properties were assessed through the convergent construct validity, using the Brazilian version of the Attentional Function Index and the Portuguese-language version of the Profile of Mood States instrument, while the reliability was measured by its internal consistency, expressed by the Cronbach Alpha Coefficient. Results: The Cronbach Alpha Coefficient was 0.86 for the total score, and varied from 0.64 to 0.86 in the three subscales. A strong significant negative correlation $(r=-0.64 ; p<0.0001)$ was obtained for the convergent validity. Conclusion: The Brazilian version of the Attentional Function Index resulted in satisfactory levels of validity and reliability, demonstrating its viability for use in practice and in undertaking further research.
\end{abstract}

Descriptors: Attention; Translation; Validation Studies.

\footnotetext{
${ }^{1}$ RN, MSc.

${ }^{2} \mathrm{PhD}$, Associate Professor, Faculdade de Enfermagem, Universidade Estadual de Campinas, Campinas, SP, Brazil.
} 


\section{Introduction}

Human behavior may be understood under three functional systems: cognition, which refers to the aspects of behavior related to the handling of information; emotion, which refers to feelings and motivations; and the executive functions, understood as the forms of expression of behavior ${ }^{(1)}$.

Cognition may be understood as a general term for the processing of thought, perception and judgment ${ }^{(1)}$, and may be classified as receptive functions (abilities for selecting, acquiring, classifying and integrating information), memory and learning (stored and accessed information), thought (organization and mental reorganization of information) and expressive functions (means through which the information is expressed or becomes an action $)^{(1)}$.

There are also the variations of mental activities, understood as characteristics of behavior involved in the mental processes' efficiency. These may be classified in three categories: level of consciousness (level at which the organism is receptive or not to the stimuli); activities of attention (abilities or processes which make the organism receptive to the stimuli, whether these are internal or external); activities of reason (speed with which the mental activities are performed and the speed of the motor responses)(1). Thus, attention permeates the cognitive functions and contributes in the development of the mental processes.

The ability to concentrate, that is, the capacity to direct attention (CDA) is essential for the performance of any human being's activities of daily living. The simple fact of "paying attention" involves complex neurocognitive processes ${ }^{(2)}$ and requires the person to use mental effort.

Attention is described as the concentration of the mind on an object or thought, in spite of various other stimuli occurring simultaneously ${ }^{(3)}$. The CDA, on the other hand, depends on a series of neural inhibitory mechanisms which act by blocking stimuli and competing distractions which may happen during an arranged activity. ${ }^{(4)}$.

One of the ways an individual can deal with the problem of the complexity of information and stimuli is to focus his or her attention on just a few aspects, judged to be the most relevant, in a determined period of time, and ignore the rest. As it is not possible to be attentive to everything at the same time, certain objects or activities are selected for perception, while others are ignored(1). $^{(1)}$
To understand how an individual can be distracted in different directions, and why particular situations can be unpleasant or stressful, it is necessary to understand two of the mechanisms of attention, which are distinct in terms of the effort involved in their use. One of them, termed involuntary attention, is based in interests and does not require the use of mental effort; while the other - termed voluntary or directed attention - is used when it is necessary to pay attention to something which is not necessarily interesting, and depends on mental effort ${ }^{(4-5)}$.

The key point involved is the concept of inhibition, as what maintains the focus on a specific thought is not the reinforcement in this specified mental activity, but rather the inhibition of everything that there is around. Thus, inhibiting the competing distractions helps the individual to sustain or maintain the original focus of attention $^{(4-5)}$.

Directed attention is fundamental in daily life, as it is important to complete a flow of thought, to learn new information, to plan activities, to carry out self-care, to think clearly, and to maintain intentional activity despite environmental distractions ${ }^{(2-6)}$. In Brazil, situations demanding attention have been the focus of studies with nurses $^{(7)}$ and patients ${ }^{(8-9)}$, with instruments therefore being needed for evaluating these individuals' CDA.

There are subjective and objective measures for examining CDA in healthy people and those with health problems, such as chronic illnesses. As objective measures, there are the Digit Span Forward (DSF) and the Digit Span Backward (DSB), both used for assessing the CDA of an individual. (10) As a subjective measure, there is the Attentional Function Index $(A F I)^{(2)}$, which has been used in studies involving people with chronic health problems ${ }^{(2,10-11)}$ and in healthy individuals ${ }^{(12-13)}$.

The AFI is an instrument of subjective assessment and aims to measure how the person assesses his or her functioning in specified situations which require concentration. The first version of this was developed with 16 items, on a scale of the visual analogic type going from zero to $100 \mathrm{~mm}$, with two extremes(11), and was used in diverse populations ${ }^{(2,13-15)}$. One study in Brazil ${ }^{(16)}$ evaluated nurses' perception of attentional functioning, using the version of the AFI with 16 items, and showed a negative association between the situations of attentional demand and the ability to direct attention - that is, the greater the situation of attentional demand, the lower the nurses perceived their attentional functioning.

The most recent version of the AFI is made up of 13 items with three subscales: Effective action (7 items) 
which evaluated the functioning perceived by the person during their activities of daily living which demand mental effort; Attentional lapses (3 items), which evaluated the difficulties perceived during tasks which require concentration, and Interpersonal effectiveness (3 items), which measures how the person perceives his or her interaction in specified circumstances and events which depend for attention on inhibitory efforts $^{(11)}$. The AFI has satisfactory reliability, with an internal consistency coefficient varying between 0.84 and 0.94 in studies with healthy people and people with health problems ${ }^{(2,10-12,14,17)}$. Regarding the AFI's validity, the construct validity was assessed using exploratory factorial analysis, which resulted in a scale with 13 items, and the divergent and convergent construct validity was assessed, showing correlations with the measurements of assessment of concentration and confusion state by the POMS ${ }^{(11)}$.

The students are considered healthy individuals who can experience different sources of attentional demands such that their cognitive performance is influenced, including when this is detrimental to the carrying-out of academic activities. In this context, the use of instruments capable of assessing attentional functioning - such as the AFI - can contribute to the teaching of nursing, through the evaluation of the performance of daily activities, which is directly related to the undergraduates' level of attention.

After Professor Cimprich had given her approval, the AFI, in its new version, with 13 items ${ }^{(11)}$ was translated and adapted to the Brazilian culture following the stages recommended in the international literature(18): translation from English to Portuguese, back-translation of the instrument into English, evaluation by a group of judges, and the carrying-out of a pre-test. In this study, the choice of the AFI was justified due to its being a subjective measurement of assessment of attention involving both people with chronic health problems and healthy individuals, and due to its presenting satisfactory psychometric properties of validity and reliability.

Considering the importance of evaluating the instrument's psychometric properties after the process of cultural adaptation, this study's objective was to evaluate the reliability and validity of the Brazilian version of the AFI.

\section{Method}

This is a methodological study, characterized by testing of data collection instruments. The participants were students from the undergraduate nursing course of a university in the state of São Paulo.

The study obtained a favorable decision from the institution's Research Ethics Committee (Process $\left.n^{\circ} 235 / 2005\right)$. After the subjects had been invited to participate and their consent had been obtained, they were requested to sign the Terms of Free and Informed Consent.

Data collection was undertaken by the researcher over two consecutive weeks. In the first week, collection took place with the $3^{\text {rd }}$ and $4^{\text {th }}$ year students, and in the second, with the students from the $1^{\text {st }}$ and $2^{\text {nd }}$ years. The subjects were approached in the classroom and while in possession of the self-administered instruments, and were advised to hand them in to the researcher after filling them out.

The Brazilian version of the AFI (B-AFI), the Portuguese-language version of the Profile of Mood States $(P O M S)^{(19)}$ and a file for socio-demographic characterization were used for data collection.

The Brazilian version of the AFI is made up of 13 items and its subjects are requested to draw a mark along a response line, on a visual analog scale, which best describes their perception in regard to the performance of the activities related to each one of the items. A general score is based on the sum of each score and the average of all the items. High scores represent high levels of perception of attentional functioning and low scores represent low perception of attentional functioning ${ }^{(2,15)}$.

The POMS is a self-administered instrument for evaluating mood. It is composed of 65 words, distributed in six domains: tension ( 9 items); depression (15 items); anger (12 items); vigor ( 8 items); fatigue ( 7 items); confusion ( 7 items); and friendliness ( 7 items), which describe feelings on a Likert-type scale with five points: $0=$ nothing, $1=$ a little, $2=$ more or less, $3=$ significantly, $4=$ extremely $^{(19)}$.

The scores are obtained by summing each domain's averages; the higher the score, the greater the presence of alterations in the mood state. It is emphasized that the POMS, as well as its domains, has been correlated with the AFI in studies with students ${ }^{(13)}$ and women with breast cancer(11,15).

It is stressed that for the correlation of the instruments regarding meaning and magnitude, the following hypothesis was considered: that there is a strong negative correlation between the Brazilian version of the AFI and the Portuguese-language version of the POMS, as the greater the perceived attentional functioning, the lower the alteration in the mood state. 
For the analysis, students who reported a previous or ongoing history of mental problems were excluded, as were those who mentioned using medications which can interfere in cognition. This information was presented by the participants in the socio-demographic characterization file.

The data was organized using the program ExcelWindows/XP, and was analyzed by the statistical services using the Statistical Analysis System (SAS - System for Windows) program, version 9.1 .3 - 2002/2003. Descriptive statistics (measurements of position, standard-deviation and percentages) were used to analyze the sample and the instruments. The average of the scoring from the subjects' responses was obtained from the total of the items and for each subscale of the B-AFI. In the case of the POMS, the sum of the subjects' responses for each subscale was obtained.

The reliability of the total of the items and of the subscales of the B-AFI was analyzed in terms of its internal consistency using the Cronbach Alpha Coefficient, with a minimum acceptable limit of $0.70^{(20)}$.

The B-AFI's subscales' validity was evaluated using validity of the convergent type of construct, using the Portuguese-language version of the POMS. The convergent construct validity was expressed by the Pearson co-efficient, which verifies a linear association between two variables(20). This co-efficient can present values varying between -1.00 (a perfect negative correlation), 0.0 (absence of correlation), and +1.0 (perfect positive correlation).

To assess the magnitude of the correlation coefficient, values from 0.1 to 0.3 are considered a weak linear correlation, 0.3 to 0.5 , a moderate linear correlation, and over 0.5 , a strong linear correlation(21). For the statistical tests, the level of significance of $5 \%$ was considered $(\alpha=0.05)$.

\section{Results}

The sample was made up of 138 nursing students from a public university in the state of São Paulo, with an average age of 21.6 ( $\mathrm{sd}=2.5$ ) years. The majority was female $(94.9 \%)$, single $(92.7 \%)$ and mentioned having some type of leisure activity (68.8\%).
In relation to housing, $31.9 \%$ of the students live with their parents in the city of Campinas, $29.7 \%$ live in housing shared by students and $9.4 \%$ live in university accommodation. The majority of the students does not work, does not participate in research projects and does not undertake extra-curricular placements (Table 1 ).

Table 1 - Distribution of frequencies and percentages of the nursing students' socio-demographic characteristics. Campinas, São Paulo, Brazil, 2011

\begin{tabular}{|c|c|c|}
\hline \multirow{2}{*}{ Characteristics } & \multicolumn{2}{|c|}{ Sample distribution } \\
\hline & $\mathbf{n}$ & $\%$ \\
\hline \multicolumn{3}{|l|}{ Sex } \\
\hline Female & 131 & 94.9 \\
\hline Male & 7 & 5.1 \\
\hline \multicolumn{3}{|l|}{ Year of course } \\
\hline $1^{\text {st }}$ & 35 & 25.4 \\
\hline $2^{\text {nd }}$ & 32 & 23.2 \\
\hline $3^{\text {rd }}$ & 38 & 27.5 \\
\hline $4^{\text {th }}$ & 33 & 23.9 \\
\hline \multicolumn{3}{|l|}{ Marital status } \\
\hline Single & 128 & 92.7 \\
\hline Married & 8 & 5.8 \\
\hline Living with Partner & 2 & 1.4 \\
\hline \multicolumn{3}{|l|}{ Where lives and with whom } \\
\hline Parents, in Campinas & 44 & 31.9 \\
\hline Parents in other city & 16 & 11.6 \\
\hline Student house in Campinas & 41 & 29.7 \\
\hline Uni. accommodation & 13 & 9.4 \\
\hline Alone in Campinas & 10 & 7.2 \\
\hline Other & 14 & 10.1 \\
\hline \multicolumn{3}{|l|}{ Leisure activity } \\
\hline No & 43 & 31.2 \\
\hline Yes & 95 & 68.8 \\
\hline \multicolumn{3}{|l|}{ Work } \\
\hline No & 126 & 91.3 \\
\hline Yes & 12 & 8.7 \\
\hline \multicolumn{3}{|l|}{ Engaged in research } \\
\hline No & 111 & 80.4 \\
\hline Yes & 27 & 19.6 \\
\hline \multicolumn{3}{|l|}{ Extra-curricular placements } \\
\hline No & 119 & 86.2 \\
\hline Yes & 19 & 13.8 \\
\hline \multicolumn{3}{|l|}{ Scholarship* } \\
\hline No & 106 & 76.8 \\
\hline Yes & 32 & 23.2 \\
\hline
\end{tabular}


Table 2 - Descriptive analysis of the Brazilian version of the Attention Function Index. Campinas, São Paulo, Brazil, 2011

\begin{tabular}{|c|c|c|c|c|}
\hline Brazilian version of $\mathrm{AFI}$ & Average & SD* $^{*}$ & $\mathbf{r}^{\dagger}$ & Variation \\
\hline Iniciar atividades (tarefas, trabalhos) que pretendo realizar & 46.8 & 20.3 & 0.58 & $5-99$ \\
\hline Dar continuidade na realização dos planos & 49.0 & 23.8 & 0.59 & $2-99$ \\
\hline Fazer coisas que leva tempo e exige esforço & 45.4 & 23.4 & 0.66 & $0-100$ \\
\hline Tomar decisões & 55.5 & 24.6 & 0.55 & $1-100$ \\
\hline Concentrar-me no que eu faço & 48.0 & 24.4 & 0.69 & $0-98$ \\
\hline Lembrar de fazer todas as coisas que me propus a fazer & 46.4 & 26.7 & 0.63 & $0-100$ \\
\hline Ficar atento ao que os outros estão dizendo & 56.1 & 23.2 & 0.53 & $6-100$ \\
\hline Evitar dizer ou fazer coisas que não quero & 53.6 & 25.5 & 0.47 & $0-100$ \\
\hline Ter paciência com os outros & 50.9 & 27.0 & 0.44 & $0-100$ \\
\hline Ter dificuldade para me concentrar nos detalhes ${ }^{\ddagger}$ & 50.6 & 23.0 & 0.38 & $0-97$ \\
\hline Cometer erros no que faço ${ }^{\ddagger}$ & 57.5 & 18.6 & 0.42 & $3-97$ \\
\hline Esquecer de fazer coisas importantes ${ }^{\ddagger}$ & 59.6 & 23.9 & 0.54 & $11-100$ \\
\hline Ficar facilmente aborrecido ou irritado $\neq$ & 44.6 & 26.4 & 0.39 & $0-95$ \\
\hline
\end{tabular}

*Standard deviation

†Pearson correlation coefficient

†Items with inverted values

The reliability of the Brazilian version of the AFI was assessed by calculating the Cronbach Alpha Coefficient, which demonstrated satisfactory internal consistency for all the instrument's items, with a score of 0.86 , found also for the subscales (Table 3).

Table 3 - Average, standard deviation and internal consistency of the subscales of the Brazilian version of the AFI. Campinas, São Paulo, Brazil, 2011

\begin{tabular}{lccc}
\hline & Subscale & Average & Standard deviation \\
\hline Effective action & 50.2 & 17.4 & 0.86 \\
Attentional lapses & 55.9 & 16.9 & 0.65 \\
Interpersonal effectiveness & 49.7 & 20.1 & 14.7 \\
Total of items & 51.1 & 0.64 \\
\hline
\end{tabular}

For evaluating the validity of the convergent construct the total of the items of the Brazilian version of the AFI was correlated with the sum of the items from the Portuguese-language version of the POMS. This indicated a strong negative correlation $(r=-0.64$; p-value $<0.0001$ ).

\section{Discussion}

The subjects are a group of young students, the majority of whom are female, single, resident in the city of Campinas, and who carry out some form of leisure activity. The majority of the students does not work, does not participate in research projects and does not undertake extra-curricular placements.

The reliability analysis indicates that the Brazilian version of the AFI resulted in high internal consistency $(\alpha=0.86)$, which corroborates other studies which analyzed the internal consistency of the Attentional
Function Index with both healthy individuals and people with health problems, with Cronbach Alpha values between 0.84 and $0.96^{(2,10-12,14,17)}$.

A strong negative correlation was obtained $(r=-0.64$; $\mathrm{p}<0.0001$ ) between the Brazilian version of the AFI and the Portuguese-language version of the POMS, evidencing validity and reliability for use in the Brazilian culture.

It is noteworthy that the initial hypothesis regarding the meaning and magnitude was confirmed - that is, the greater the perception of attentional functioning, the lower the POMS score, meaning that the alteration of mood presented by the student was lower.

It stands out that the negative correlation between these two instruments is owed to the fact that high values on the POMS score represent a high level of alteration of mood state, while high values of the AFI represent a good perception of functioning - that is, they represent 
what the individual judges to be good attentional functioning. Thus, a negative correlation is expected between these two instruments. It is noteworthy that the POMS, along with its domains, has been correlated with the AFI in research with students ${ }^{(12)}$ and women with breast cancer(10-11,14,22).

To evaluate its reliability and validity in other populations, however, further studies are necessary, as this study was conducted only among nursing students.

\section{Conclusion}

The present study showed that the Brazilian version of the AFI is a valid instrument for measuring how a person evaluates their functioning in the face of specified situations requiring concentration. Although it has demonstrated good acceptability and psychometric properties, further studies will be necessary to evaluate its reliability and validity in other groups of individuals.

Researchers and clinicians can benefit from the use of this instrument with a view to evaluating cognitive suffering, especially the efficiency perceived in the functions used in routine activities, both among healthy people and among those with health problems.

Thus, it may be concluded that the Brazilian version of the AFI may be used safely to measure the theoretical concept it is proposed to measure, for populations similar to that studied.

\section{References}

1. Lezak MD, Howieson DB, Loring DW. Neuropsychological assessment. 4th ed. Oxford University Press: New York; 2004.

2. Cimprich B. Attentional fatigue following breast cancer surgery. Res Nurs Health. 1992; 15:199-207. doi: $10.1002 /$ nur.4770150306.

3. James W. The principles of psychology. Vol 1. New York: Cosimo; 2007. [original work published in 1890].

4. Kaplan S, Kaplan R. Cognition and environment: functioning in an uncertain world. Michigan: Ulrich's; 1983.

5. Kaplan S. The restorative benefits of nature: toward an integrative framework. J Environ Psychol. 1995;15(3):169-82. doi:10.1016/02724944(95)90001-2.

6. Cimprich B. Age and extent of surgery affect attention in women treated for breast cancer. Res Nurs Health. 1998;21:229-38. doi:10.1002/(SICI)1098240X(199806)21:3<229.

7. Santos LSC, Guirardello EB. Nurses' attention demands in the work setting. Rev. Latino-Am. Enfermagem.
2007;15(1):27-33.

8. Pontes L, Guirardello EB, Campos CJG. Demandas de atenção de um paciente na unidade de transplante de medula óssea. Rev Esc Enferm USP. 2007;41(1):154-60. 9. Reis CK, Guirardello EB, Campos CJG. O indivíduo renal crônico e as demandas de atenção. Rev Bras Enferm. 2008;61(3):336-41.

10. Lehto R, Cimprich B. Anxiety and directed attention in women awaiting breast cancer surgery. Oncol Nurs Forum. 1999;26(4):767-72.

11. Cimprich B, Visovatti $M$, Ronis DL. The attentional function index - a self report cognitive measure. PsychoOncol. 2011;20(2):194-202.doi:10.1002/pon.1729.

12. Tennessen CM, Cimprich B. Views to nature: effects on attention. J Environ Psychol. 1995;15:77-85. doi:10.1016/0272-4944(95)90016-0.

13. Sanders CM, Yankou D, Andrusyszyn MA. Attention and restoration in post-RN students. J Contin Educ Nurs. 2005;36(5):218-25.

14. Cimprich B, So $H$, Ronis DL, Trask C. Pre-treatment factors related to cognitive functioning in women newly diagnosed with breast cancer. Psycho-Oncology. 2005; 14(1):70-8. doi: 10.1002/pon.821.

15. Lethbridge $K$, Yankou D, Andrusyszyn MA. The effects of a restorative intervention on undergraduate nursing student's capacity to direct attention. J Holist Nurs. 2005;23(3):329-47. doi:10.1177/0898010105279610.

16. Roscani, ANCP, Guirardello EB. Attention demands in the workplace and the capacity to direct attention of nurses. Rev. Latino-Am. Enfermagem. 2010;18(4):778-85.

17. Stark MA. Relationship of psychosocial tasks of pregnancy and attentional functioning in the third trimester. Res Nurs Health. 2001; 24:194-202. doi: 10.1002/nur.1022.

18. Beaton DE, Bombardier C, Guillemin F, Ferraz MB. Recommendations for the cross-cultural adaptation of the DASH \& QuickDASH outcome measures. Am Acad Orthop Surg. 2007;3-13.

19. Peluso, MAM. Alterações de humor associadas à atividade física intensa. [tese de doutorado]. São Paulo (SP): Universidade de São Paulo; 2003.

20. Hair JF, Black WC, Babin B, Anderson RE, Tatham RL. Multivariate data analysis. 6th ed. Prentice-Hall: New Jersey; 2009.

21. Burns N, Grove SK. The practice of nursing research: conduct, critique \& utilization. 4th ed. Philadelphia, PA: Saunders; 2001.

22. Cimprich B. Pretreatment symptom distress in women newly diagnosed with breast cancer. Cancer Nurs. $1999 ; 22(3): 185-94$. 